10,400 metres is how far Google Maps Australia recommends you should travel to get from 200 Sussex Street in Sydney across the road to 201 Sussex Street.

Aus $\$ 3.00$ is the toll you must pay (roughly US $\$ 2.35$ ) to cross Sydney Harbour Bridge as part of Google's suggested route.

300 metres is the actual, toll-free, distance between the two buildings - one of which just happens to be Google's Sydney headquarters.

\section{SCORECARD}

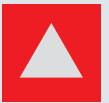

\section{Chinese romance} Shanghai restaurateurs are serving sweet potatoes grown from seeds that went into space on last year's Shenzhou VI mission. The star-crossed spuds are purple - the traditional Chinese colour of romance.

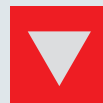

Nagging Constant nagging really does seem to be counter-productive. In a recent experiment, volunteers completed anagrams more slowly when the face of a nagging loved one was flashed subliminally on a screen. Faces of fun-loving friends and family had no such effect.

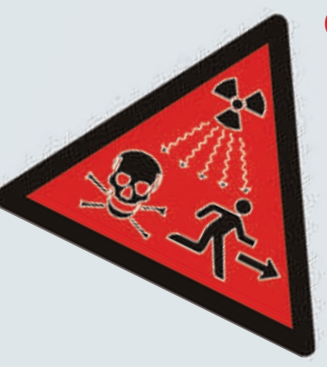

\section{ON THE} RECORD C(Danger, stay away.)

The message conveyed by the new 'crystal clear' radiation warning sign designed by the International Atomic Energy Agency. Looks good, although it does seem to advocate running in the workplace.

\section{c(Tenure is not an} inoculation against foolishness."

University of Maryland physicist Robert Park's opinion on the work of Robert Jahn, whose Princeton University tenure allowed him to run a lab investigating telekinesis.

Sources: TechCrunch, BBC, J. Exp. Soc. Psychol., Reuters

\title{
Role of state climatologist comes under scrutiny
}

Many climate scientists get frustrated with those who don't believe that human activity is causing global warming, but should having such views be a sackable offence? In recent months, two US state climatologists have been asked to stand down from their posts because of it, triggering debate about whether personal views should determine suitability for what many see as an academic position.

Almost all US states have their own climatologist, who runs a small office concerned with meteorological matters of local interest. Earlier this month, Oregon governor Ted Kulongoski said that he wants to strip Oregon's climatologist George Taylor of his title for not agreeing that global warming is predominantly caused by humans.

Taylor, based at Oregon State University in Corvallis and appointed to his post in 1991, argues that his post is academic rather than political, and that it's not his job to tell the state government what to do. "Most state climatologists have never even met their governor, let alone offered policy advice," he told Nature. Therefore, he says, his personal views on climate change shouldn't be an issue.

But Kulongoski clearly believes that a state climatologist should represent the state, and he argues that Taylor's views are inconsistent with Oregon's goal of cutting greenhouse-gas emissions. "He is Oregon State University's climatologist," Kulongoski said in a television interview on 8 February. "He is not the state of Oregon's climatologist."

Patrick Michaels, Virginia's climatologist since 1980, faces a similar situation. An environmental scientist at the University of Virginia, he does not agree that taking action to cut greenhouse-gas emissions is an urgent priority. Last August, he received a letter from the office of the governor, Timothy Kaine, asking him not to use the title any more.

Most state climate offices, like those of Michaels and Taylor, are based at state universities, although a few are directly within state government. Thirty-four of the state climatological offices are officially recognized by the American Association of State Climatologists (AASC), which sets standards for state climate offices, but cannot bestow or remove 'state climatologist' status. To qualify for AASC recognition, an office must make its data public, set up educational initiatives and work with the media. It must also monitor climate conditions, place them in historical context and assess possible future impacts on the climate.

The role is somewhere between that of a meteorologist and a climate modeller, and state climatologists are concerned only with their own state. Residents of New Jersey, for example, can thank their state climatologist David Robinson for the knowledge that they have just encountered their warmest December since records began in 1895 .

So grand ideas about the need to tackle global warming aren't the main focus, says Mark Shafer, a climate officer who works with Oklahoma state climatologist and former AASC president Ken Crawford. Although stopping short of saying that state climatologists shouldn't be sacked for their views on global warming, he points out that they generally deal with questions to which those views aren't relevant - for example, the impact of human actions on shorter-term climate effects such as drought.

The AASC is now preparing a statement in response to the controversy, urging state governors to consider the factors most important for a successful state climate office. "We encourage public officials to enter into a direct dialogue with their respective state climatologists in order to resolve any differences of opinion," says a draft of the letter, seen by Nature. Shafer says there are roughly a dozen prospective signatories so far.

Many state climatologists are unhappy about the growing importance of global climate issues on their agenda, however, and the way state climatologists' views on global warming (particularly those of the sceptics) are increasingly sought by the media. Taylor points out that the role initially grew from the National Weather Service in the 1950s, and has always been more closely akin to a weather information service. "Climatologists must be knowledgeable about climate change, but that is usually only a very small part of what we do," he argues.

All of which moves the debate towards a different question. As the priorities of a state change, should those of its climatologist?

Michael Hopkin 